Preprint typeset in JINST style - HYPER VERSION

\title{
Study of the effects induced by lead on the emulsion films of the OPERA experiment
}
A. Anokhina ${ }^{22}$, S. Aoki ${ }^{16}$, A. Ariga ${ }^{23}$, L. Arrabito ${ }^{18}$, D. Autiero ${ }^{18}$, A. Badertscher ${ }^{36}$, F. Bay ${ }^{1}$, A. Bergnoli ${ }^{28}$, F. Bersani Greggio ${ }^{33}$, M. Besnier ${ }^{2}$, D. Bick ${ }^{13}$, C. Bozza ${ }^{31}$, T. Brugiere ${ }^{18}$, R. Brugnera ${ }^{29}$, G. Brunetti ${ }^{8}$, S. Buontempo ${ }^{24}$, E. Carrara ${ }^{29}$, A. Cazes ${ }^{11}$, L. Chaussard ${ }^{18}$, M. Chernyavsky ${ }^{21}$, V. Chiarella ${ }^{11}$, N. Chon-Sen ${ }^{32}$, A. Chukanov $^{24}$, L. Consiglio ${ }^{8}$, M. Cozzi $^{8}$, F. Dal Corso ${ }^{28}$, G. D'Amato ${ }^{31}$, N. D’Ambrosioº, G. De Lellis ${ }^{25}$, Y. Déclais ${ }^{18}$, M. De Serio ${ }^{5}$, F. Di Capua ${ }^{24}$, D. Di Ferdinando ${ }^{7}$, A. Di Giovanni ${ }^{17}$, N. Di Marco ${ }^{17}$, C. Di Troia ${ }^{11}$, S. Dmitrievski ${ }^{10}$, A. Dominjon ${ }^{18}$, M. Dracos ${ }^{32}$, D. Duchesneau ${ }^{2}$, B. Dulach ${ }^{11}$, S. Dusini ${ }^{28}$, J. Ebert ${ }^{13}$, O. Egorov ${ }^{20}$, R. Enikeev ${ }^{19}$, A. Ereditato ${ }^{6}$, L. S. Esposito ${ }^{3}$, J. Favier $^{2}$, G. Felici ${ }^{11}$, T. Ferber ${ }^{13}$, R. Fini ${ }^{5}$, A. Franceschi ${ }^{11}$, T. Fukuda ${ }^{23}$, C. Fukushima ${ }^{12}$, V. I. Galkin ${ }^{22}$, V. A. Galkin ${ }^{27}$, A. Garfagnini ${ }^{29}$, G. Giacomelli ${ }^{8}$, M. Giorgini $^{8}$, C. Goellnitz ${ }^{13}$, D. Golubkov ${ }^{20}$, Y. Gornoushkin ${ }^{10}$, G. Grella ${ }^{31}$, F. Grianti ${ }^{33}$, M. Guler ${ }^{1}$, G. Gusev ${ }^{21}$, C. Gustavino ${ }^{3}$, C. Hagner ${ }^{13}$, T. Hara ${ }^{16}$, M. Hierholzer ${ }^{13}$, S. Hiramatsu ${ }^{23}$, K. Hoshino ${ }^{23}$, M. leva ${ }^{5}$, K. Jakovcic ${ }^{35}$, J. Janicsko Csathy ${ }^{26}$, B. Janutta ${ }^{13}$, C. Jollet $^{32}$, F. Juget ${ }^{26}$, T. Kawai ${ }^{23}$, M. Kazuyama ${ }^{23}$, S. H. Kim ${ }^{14,}$, , M. Kimura ${ }^{12}$, J. Knuesel ${ }^{6}$, K. Kodama ${ }^{15}$, M. Komatsu ${ }^{23}$, U. Kose ${ }^{1}$, I. Kreslo ${ }^{6}$, I. Laktineh ${ }^{18}$, C. Lazzaro ${ }^{36}$, J. Lenkeit ${ }^{13}$, A. Ljubicic ${ }^{35}$, A. Longhin ${ }^{28}$, G. Lutter ${ }^{26}$, K. Manai ${ }^{18}$, G. Mandrioli ${ }^{7}$, S. Manzoor ${ }^{8,} b$, A. Marotta ${ }^{24}$, J. Marteau ${ }^{18}$, H. Matsuoka ${ }^{23}$, N. Mauri ${ }^{8}$, F. Meisel ${ }^{26}$, A. Meregaglia ${ }^{32}$, M. Messina ${ }^{6}$, P. Migliozzi ${ }^{24}$, S. Miyamoto ${ }^{23}$, P. Monacelli ${ }^{17}$, K. Morishima ${ }^{23}$, U. Moser ${ }^{6}$, M. T. Muciaccia ${ }^{4}$, N. Naganawa ${ }^{23}$, T. Naka ${ }^{23}$, M. Nakamura ${ }^{23}$, T. Nakamura ${ }^{23}$, T. Nakano ${ }^{23}$, V. Nikitina ${ }^{22}$, K. Niwa ${ }^{23}$, Y. Nonoyama ${ }^{23}$, S. Ogawa ${ }^{12}$, V. Osedlo ${ }^{22}$, D. Ossetski ${ }^{27}$, A. Paoloni ${ }^{11}$, B.D. Park ${ }^{14}$, I. G. Park ${ }^{14}$, A. Pastore ${ }^{4}$, L. Patrizii ${ }^{7}$, E. Pennacchio ${ }^{18}$, H. Pessard ${ }^{2}$, C. Pistillo ${ }^{6}$, N. Polukhina ${ }^{21}$, M. Pozzato ${ }^{7}$, K. Pretzl ${ }^{6}$, P. Publichenko ${ }^{22}$, F. Pupilli ${ }^{17}$, T. Roganova ${ }^{22}$, G. Rosa ${ }^{30}$, I. Rostovtseva ${ }^{20}$, A. Rubbia ${ }^{36}$, A. Russo ${ }^{24}$, O. Ryazhskaya ${ }^{19}$, D. Ryzhikov ${ }^{27}$, Y. Sato ${ }^{34}$, O. Sato ${ }^{23}$, V. Saveliev ${ }^{27}$, G. Sazhina ${ }^{22}$, A. Schembri ${ }^{3}$, L. Scotto Lavina ${ }^{24}$, H. Shibuya ${ }^{12}$, S. Simone ${ }^{4}$, M. Sioli $^{8}$, C. Sirignano ${ }^{31}$, G. Sirri ${ }^{7}$, J. S. Song ${ }^{14}$, M. Spinetti ${ }^{11}$, L. Stanco ${ }^{28}$, N. Starkov ${ }^{21}$, M. Stipcevic ${ }^{35}$, T. Strauss ${ }^{36}$, P. Strolin ${ }^{25}$, V. Sugonyaev ${ }^{29}$, Y. Taira ${ }^{23}$, S. Takahashi ${ }^{23}$, M. Tenti ${ }^{8}$, F. Terranova ${ }^{11}$, V. Tioukov ${ }^{24}$, V. Togo ${ }^{7}$, P. Tolun ${ }^{1}$, V. Tsarev ${ }^{21}$, S. Tufanli ${ }^{1}$, N. Ushida ${ }^{15}$, C.. Valieri ${ }^{7}$, P. Vilain ${ }^{9}$, M. Vladimirov ${ }^{21}$, L. Votano ${ }^{11}$, J. L. Vuilleumier ${ }^{26}$, G. Wilquet ${ }^{9}$, B. Wonsak ${ }^{13}$, J. Wurtz ${ }^{32}$, C. S. Yoon ${ }^{14}$, J. Yoshida ${ }^{23}$, Y. Zaitsev ${ }^{20}$, S. Zemskova ${ }^{10}$, A. Zghiche ${ }^{2}$, and R. Zimmermann ${ }^{13}$. 
${ }^{1}$ METU-Middle East Technical University, TR-06531 Ankara, Turkey

${ }^{2}$ LAPP, Université de Savoie, CNRS/IN2P3, 74941 Annecy-le-Vieux, France

${ }^{3}$ Laboratori Nazionali del Gran Sasso dell'INFN, 67010 Assergi (L'Aquila), Italy

${ }^{4}$ Dipartimento di Fisica dell'Università di Bari and INFN, 70126 Bari, Italy

${ }^{5}$ INFN Sezione di Bari, 70126 Bari, Italy

${ }^{6}$ University of Bern, $\mathrm{CH}-3012$ Bern, Switzerland

${ }^{7}$ INFN Sezione di Bologna, I-40127 Bologna, Italy

${ }^{8}$ Dipartimento di Fisica dell'Università di Bologna and INFN, I-40127 Bologna, Italy

${ }^{9}$ IIHE-Inter-University Institute for High Energies, Université Libre de Bruxelles, B-1050 Brussels, Belgium

10 JINR-Joint Institute for Nuclear Research, 141980 Dubna, Russia

${ }^{11}$ INFN - Laboratori Nazionali di Frascati, 00044 Frascati (Roma), Italy

12 Toho University, 274-8510 Funabashi, Japan

${ }^{13}$ Hamburg University, 22043 Hamburg, Germany

${ }^{14}$ Gyeongsang National University, 900 Gazwa-dong, Jinju 660-300, Korea

${ }^{15}$ Aichi University of Education, 448 Kariya (Aichi-Ken), Japan

${ }^{16}$ Kobe University, 657 Kobe, Japan

${ }^{17}$ Dipartimento di Fisica dell'Università dell'Aquila and INFN, Gr. Coll. L'Aquila, Italy

${ }^{18}$ IPNL, Université Claude Bernard Lyon 1, CNRS/IN2P3, 69622 Villeurbanne, France

${ }^{19}$ INR-Institute for Nuclear Research of the Russian Academy of Sciences, 117312 Moscow, Russia

${ }^{20}$ ITEP-Institute for Theoretical and Experimental Physics, 117259 Moscow, Russia

${ }^{21}$ LPI-Lebedev Physical Institute of the Russian Academy of Sciences, 117924 Moscow, Russia

22 SINP MSU-Skobeltsyn Institute of Nuclear Physics of Moscow State University, 119992 Moscow, Russia

${ }^{23}$ Nagoya University, 464-01 Nagoya, Japan

${ }^{24}$ INFN Sezione di Napoli, 80125 Napoli, Italy

${ }^{25}$ Dipartimento di Fisica dell'Università Federico II di Napoli and INFN, 80125 Napoli, Italy

${ }^{26}$ Université de Neuchâtel, CH 2000 Neuchâtel, Switzerland

${ }^{27}$ Obninsk State University, Institute of Nuclear Power Engineering, 249020 Obninsk, Russia

${ }^{28}$ INFN Sezione di Padova, 35131 Padova, Italy

${ }^{29}$ Dipartimento di Fisica dell'Università di Padova and INFN, 35131 Padova, Italy

${ }^{30}$ Dipartimento di Fisica dell'Università di Roma "La Sapienza" and INFN, 00185 Roma, Italy

${ }^{31}$ Dipartimento di Fisica dell'Università di Salerno and INFN, 84084 Fisciano, Salerno, Italy

${ }^{32}$ IPHC, Université Louis Pasteur, CNRS/IN2P3, 67037 Strasbourg, France

${ }^{33}$ CSAAE - Urbino University and INFN-Laboratori Nazionali di Frascati

${ }^{34}$ Utsunomiya University, 320 Tochigi-Ken, Utsunomiya, Japan

${ }^{35}$ IRB-Rudjer Boskovic Institute, 10002 Zagreb, Croatia

${ }^{36}$ ETH-Eidgenössische Technische Hochschulen Zürich, CH-8092 Zurich, Switzerland

${ }^{a}$ Now at Chonnam National University

${ }^{b}$ Also PD, PINSTECH, P.O. Nilore, and COMSATS-CIIT, No. 30, H-8/1, Islamabad, Pakistan

E-mail: patrizii@bo.infn.it 
ABSTRACT: The OPERA neutrino oscillation experiment is based on the use of the Emulsion Cloud Chamber (ECC). In the OPERA ECC, nuclear emulsion films acting as very high precision tracking detectors are interleaved with lead plates providing a massive target for neutrino interactions. We report on studies related to the effects occurring from the contact between emulsion and lead. A low radioactivity lead is required in order to minimize the number of background tracks in emulsions and to achieve the required performance in the reconstruction of neutrino events. It was observed that adding other chemical elements to the lead, in order to improve the mechanical properties, may significantly increase the level of radioactivity on the emulsions. A detailed study was made in order to choose a lead alloy with good mechanical properties and an appropriate packing technique so as to have a low enough effective radioactivity.

KEYWORDS: Nuclear emulsions; OPERA experiment; lead alloy; polonium migration; $\alpha$-radioactivity.

\footnotetext{
* Corresponding author.
} 


\section{Contents}

1. Introduction 1

2. Measurements of $\alpha$-radioactivities

2.1 Measurements with nuclear emulsions

2.2 Measurements of $\alpha$-activity with a $2 \pi$ gas flow proportional counter

2.3 Measurements with Surface Barrier Silicon Detectors

2.4 Measurements with CR39 nuclear track detectors 7

2.5 Time evolution of $\alpha$-radioactivity 7

2.6 Overview on the $\alpha$-radioactivity measurements 8

2.7 Monte Carlo simulations 9

3. Effects related to the brick packaging 11

母. Effects of $\alpha$ - and $\beta$-radioactivity on emulsion scanning. 13

5. Conclusions 14

6. Acknowledgements 15

\section{Introduction}

The OPERA experiment [1] was mainly designed for the direct search of $v_{\tau}$ appearance in the pure $v_{\mu}$ CNGS beam from CERN to Gran Sasso [2]. Its observation will give a definitive proof of the neutrino oscillation interpretation of the $v_{\mu}$ disappearance observed first with atmospheric neutrinos [3-7] and then in long baseline neutrino beams [8]. The experiment is based on the use of Emulsion Cloud Chambers (ECCs) [9] and of electronic detectors. In an ECC the nuclear emulsion films act as very high precision tracking detectors, and are interleaved with plates of passive material. In the OPERA ECC the passive target material is lead.

The OPERA detector is made of two identical supermodules. Each of them consists of a neutrino target section made of lead/emulsion ECC bricks, and of a scintillator tracker detector, followed by a muon spectrometer [1]. The total neutrino target mass amounts to $1.35 \mathrm{kton}$.

The basic unit of the target, the brick, is made of 57 emulsion films interleaved with 56 lead foils of $1 \mathrm{~mm}$ thickness. The emulsion films are made of 2 emulsion layers, each $43 \mu \mathrm{m}$ thick, deposited on both sides of a $205 \mu \mathrm{m}$ thick plastic base. The beam direction is perpendicular to the emulsion films. The brick has transverse dimensions of $12.8 \times 10.3 \mathrm{~cm}^{2}$, a thickness of $8.1 \mathrm{~cm}$ and it weighs $8.3 \mathrm{~kg}$. Fast automated microscopes are used for emulsion scanning [10, 11].

The nuclear emulsions consist of silver halide micro-crystals (each of them a fewtenths of $\mu \mathrm{m}$ in size) dispersed in gelatin. The silver halide crystals are in the form of silver bromide crystals 


\begin{tabular}{|c|c|c|c|c|c|c|c|c|c|c|c|c|}
\hline & $\mathbf{A g}$ & $\mathbf{B r}$ & $\mathbf{I}$ & $\mathbf{C}$ & $\mathbf{N}$ & $\mathbf{O}$ & $\mathbf{H}$ & $\mathbf{S}$ & $\mathbf{S i}$ & $\mathbf{N a}$ & $\mathbf{S r}$ & $\mathbf{B a}$ \\
\hline $\mathbf{A}$ & 107.9 & 79.9 & 126.9 & 12 & 14 & 16 & 1 & 32 & 28 & 23 & 87.6 & 137.3 \\
\hline $\mathbf{Z}$ & 47 & 35 & 53 & 6 & 7 & 8 & 1 & 16 & 14 & 11 & 38 & 56 \\
\hline $\mathbf{\%}$ & 38.34 & 27.86 & 0.81 & 13.0 & 4.81 & 12.43 & 2.40 & 0.09 & 0.08 & 0.08 & 0.02 & 0.01 \\
\hline
\end{tabular}

Table 1. Composition of the OPERA emulsions (in \% by weight). K, F, Au, Fe and $\mathrm{Cl}$ nuclei are also present in very small amounts.

with a small amount of iodine in the crystal lattice. The density of OPERA emulsions is $\rho=2.71$ $\mathrm{g} / \mathrm{cm}^{3}$; their weight composition is given in Table 1 .

Lead is well suited as passive material of the OPERA ECC bricks due to its high density and short radiation length: the former enhances the neutrino interaction rate and the latter the momentum determination by multiple Coulomb scattering as well as electron identification and energy measurement by observing the shower development.

Natural lead contains a contamination of the radioactive isotope ${ }^{210} \mathrm{~Pb}$. Fig. 1 shows the main decay chain from ${ }^{210} \mathrm{~Pb} \rightarrow{ }^{206} \mathrm{~Pb}$. Both alpha and beta decays produce background in nuclear emulsions and may affect the event reconstruction [12]. Alpha-particles of $5.3 \mathrm{MeV}$ are emitted from the decay of ${ }^{210} \mathrm{Po}$. Fig. 目 shows the ranges of $\alpha$ particles in nuclear emulsions, lead, and CR39 ${ }^{1}$ as functions of the particle energy. The ranges were computed using the SRIM-2003 Monte Carlo code [13]. The $5.3 \mathrm{MeV} \alpha$ 's from ${ }^{210} \mathrm{Po}$ decay have a range of $25 \mu \mathrm{m}$ in nuclear emulsion. The $\beta$-radioactivity arises from the decay chain $P b^{210} \stackrel{\beta(61.5,15.0)}{\longrightarrow} B i^{210} \stackrel{\beta(1161)}{\longrightarrow} P o^{210}$ (see Fig. 11). Low and high energy $\beta$ s come from the decay of ${ }^{210} \mathrm{~Pb}$ and of ${ }^{210} \mathrm{Bi}$, respectively.

If $\alpha$-emitters are uniformly distributed inside the lead plate, because of the energy loss in lead the $\alpha$-range and energy distributions in the emulsions should be almost flat. However, in pure lead and in some lead alloys ${ }^{210}$ Po migrates to the surface layers of the lead plate [14] so that all $\alpha$ particles emitted towards the emulsion have a high probability of being detected. The alpha-activity is therefore enhanced.

We made an extensive search in order to select the least radioactive lead on the market. The DoeRun brand had a bulk activity of $\sim 27 \mathrm{~Bq} / \mathrm{kg}$, but it was not available in sufficient quantity. The lead finally used in OPERA was the Britannia brand, having a bulk activity of $\sim 80 \mathrm{~Bq} / \mathrm{kg}$.

Different types of lead alloys were obtained by adding small percentages of $\mathrm{Ca}$ or $\mathrm{Sb}$ to achieve mechanical rigidity and were tested for the OPERA bricks.

We evaluated the compatibility in relation to the packing technique of the lead and the emulsions, by measuring the single isolated grains $(f o g)$ after the emulsion development. The effect depends on the lead alloy.

A detailed study was made in order to choose a lead alloy with good mechanical properties and an appropriate packing technique so as to have low enough effective radioactivity and acceptable fog on the emulsions. We eventually decided to use the $\mathrm{PbCa} 0.03 \%$ alloy which presents good mechanical properties and was found to be safe from the point of view of $\alpha$-radioactivity and compatibility with nuclear emulsions.

\footnotetext{
${ }^{1} \mathrm{CR} 39$ is a polymer nuclear track detector (see section 2.4 )
} 


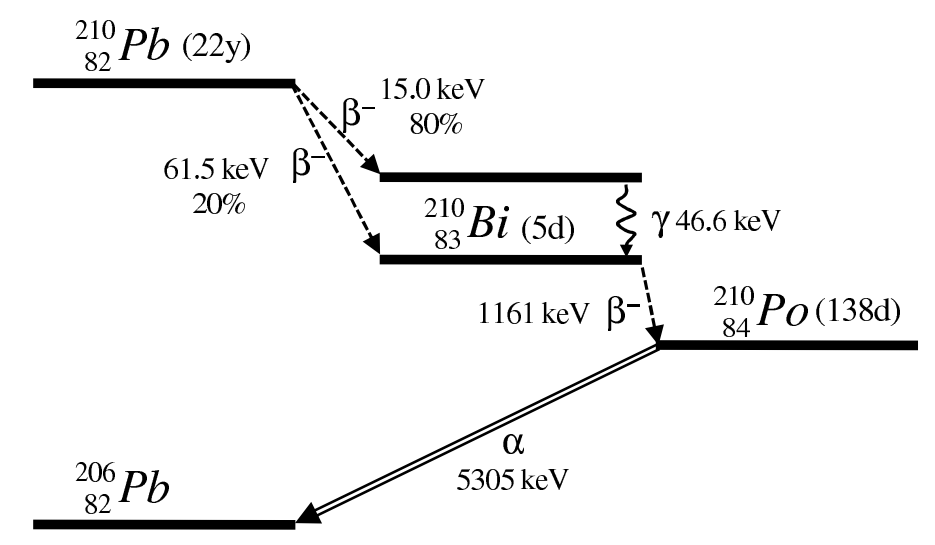

Figure 1. The decay chain ${ }^{210} \mathrm{~Pb} \rightarrow{ }^{210} \mathrm{Bi} \rightarrow{ }^{210} \mathrm{Po} \rightarrow{ }^{206} \mathrm{~Pb}$. Within parentheses the half lives of the radioactive nuclides are given.

In Section 2 the measurements of the energy, ranges and rates of $\alpha$-particles emitted from lead are presented, together with a brief description of the different methods used; the measurements are compared to Monte Carlo calculations. The effects related to the brick packaging are discussed in Section 3. The effects of the lead $\alpha$ - and $\beta$-activity on the OPERA emulsion scanning and reconstruction efficiency are studied in Section 4. The conclusions are given in Section 5.

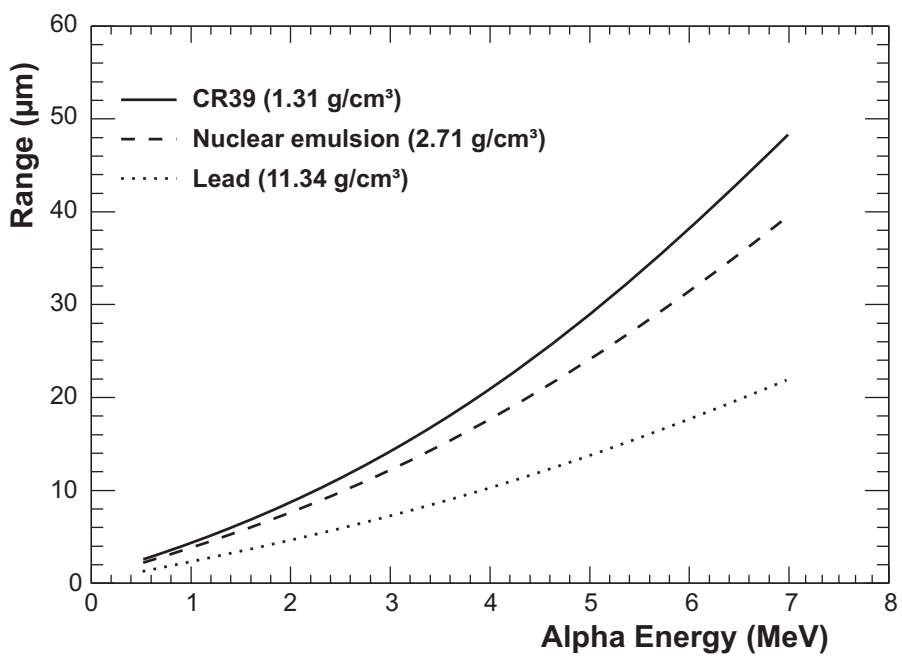

Figure 2. Ranges of alpha particles in nuclear emulsions, lead and CR39 as functions of the particle energy.

\section{Measurements of $\alpha$-radioactivities}

The $\alpha$-radioactivity of the lead samples to be tested was studied using different techniques:

(i) nuclear emulsions;

(ii) surface barrier silicon detectors (SBSiD);

(iii) $2 \pi$ gas flow proportional counter;

(iv) CR39 nuclear track detectors. 


\subsection{Measurements with nuclear emulsions}

In nuclear emulsions the passage of an ionizing particle through a micro-crystal renders it developable by chemical agents. After development, followed by fixing and washing to remove undeveloped crystals, the gelatin is transparent and the paths of charged particles are visible as trails of small dark silver grains, with a diameter smaller than $1 \mu \mathrm{m}$. A track in an emulsion layer of an emulsion film is a sequence of aligned grains and is called microtrack. A base track is a segment which connects two microtrack ends across the plastic base of the same film. It is characterised by a higher angular resolution because it is less affected by distortions and because of the larger lever arm. A volume track connects at least three base tracks observed in different emulsion films.

Alpha particles of $5 \mathrm{MeV}$ produce in the emulsions thick (black) tracks, which are not easily reconstructed as tracks by automated microscopes. They were measured semi-automatically using an objective mounted on the automated microscopes used in OPERA [10, 11]. Track lengths were determined by connecting the first and last detected grains. The emulsions were developed after several weeks in order to monitor the lead radioactivity and its time dependence. In order to compare different lead samples (pure $\mathrm{Pb}, \mathrm{PbSb}$ and $\mathrm{PbCa}$ alloys), sandwiches of lead and emulsion were prepared. Co-laminated lead samples (consisting of $1 \mathrm{~mm}$ thick lead alloy plates with a 30 $\mu \mathrm{m}$ pure DoeRun lead layer co-laminated on both sides) were also tested in order to investigate a possible reduction of the $\alpha$-emission effect.

The range distribution of $\alpha$-particles in nuclear emulsions exposed for 52 days to the $\alpha$ radioactivity of a lead $\mathrm{PbSb} 2.5 \%$ sample is shown in Fig. 3. It is compatible with a surface activity due to ${ }^{210} \mathrm{Po}$ migration, as almost all the $\alpha$ 's have the $25 \mu \mathrm{m}$ range corresponding to the $5.3 \mathrm{MeV}$ energy expected from ${ }^{210} \mathrm{Po}$ decay in absence of energy loss in lead. Notice that ranges as little as

a few $\mu \mathrm{m}$ were measured. For $\mathrm{PbCa}$ alloy samples no peak was observed but only few events for ranges smaller than $10 \mu \mathrm{m}$.

Table 2 gives the surface activity (tracks $\mathrm{cm}^{-2} \mathrm{~d}^{-1}$ ) measured for different samples and different times after lead production. The quoted errors are statistical. Systematic uncertainties are of the order of $10 \%$.

From the above measurements one can conclude that:

(i) the large $\alpha$-activity observed in $\mathrm{PbSb} 2.5 \%$ comes from a surface activity;

(ii) the $\alpha$-activities for $\mathrm{PbCa} 0.07 \%$ and $0.03 \%$ are much smaller than in $\mathrm{PbSb} 2.5 \%$ and do not come from a surface activity;

(iii) for pure lead samples the DoeRun lead is, right after production, less radioactive than the Britannia lead but the difference tends to decrease with time indicating a migration effect;

(iv) for $\mathrm{PbCa} 0.07 \%$ or $0.03 \%$ alloys, the activity is lower than for pure lead and the ${ }^{210} \mathrm{Po}$ migration seems to be limited.

(v) co-lamination of $\mathrm{PbSb}$ alloy samples with pure $\mathrm{Pb}$ does not bring any advantage in terms of reduction of the surface $\alpha$-activity. The measurements indicated the presence of large spatial fluctuations, which could be due to a non perfect co-lamination; furthermore a good uniform colamination is technically difficult to achieve.

\subsection{Measurements of $\alpha$-activity with a $2 \pi$ gas flow proportional counter}

The $\alpha$-radioactivity of different samples of pure lead and of lead alloys was measured using a 


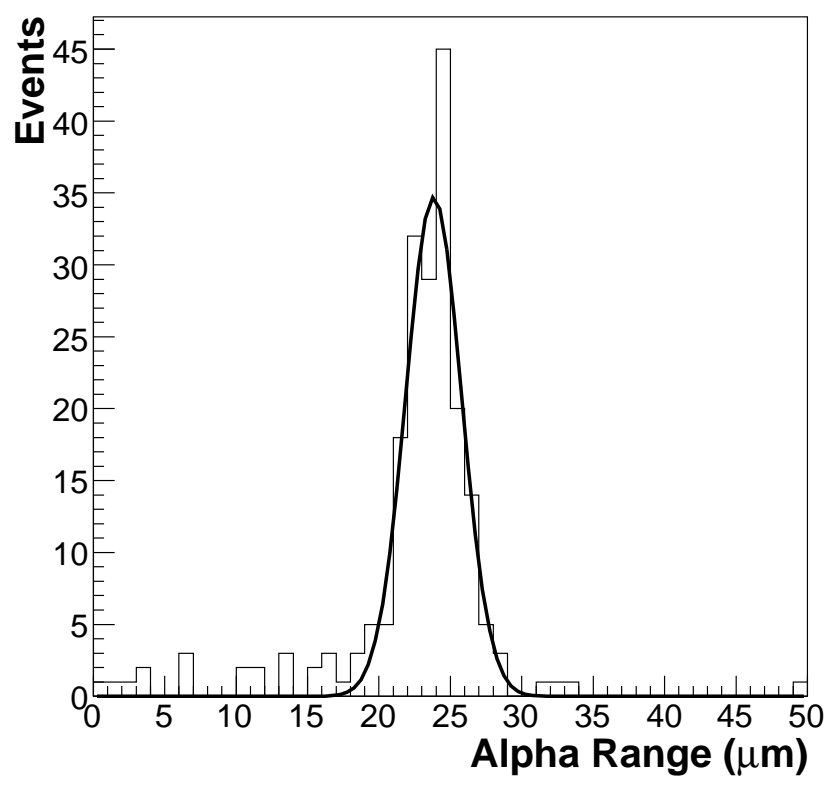

Figure 3. Ranges of $\alpha$-particles measured semi-automatically in nuclear emulsion films which were in contact with a $\mathrm{PbSb} 2.5 \%$ sample for 52 days. The peak at a range of $25 \mu \mathrm{m}$ is compatible with what is expected from a surface emission of $5.3 \mathrm{MeV} \alpha$ 's from ${ }^{210} \mathrm{Po}$ decay.

\begin{tabular}{|c|c|c|c|c|c|c|}
\hline $\begin{array}{l}\text { Primary } \\
\text { lead }\end{array}$ & $\begin{array}{c}\text { Secondary } \\
\text { component } \\
(\%)\end{array}$ & $\begin{array}{c}\text { Colamination } \\
\text { lead }\end{array}$ & $\begin{array}{c}\text { Sample } \\
\text { thickness } \\
(\mathrm{mm})\end{array}$ & \multicolumn{3}{|c|}{$\begin{array}{l}\text { Time after production } \\
\text { (weeks) }\end{array}$} \\
\hline & & & & 4 & 4 & 16 \\
\hline & & & & \multicolumn{3}{|c|}{ Surface activity (tracks $\mathrm{cm}^{-2} \mathrm{~d}^{-1}$ ) } \\
\hline DoeRun & None & None & 3 & $19.0 \pm 0.5$ & $22 \pm 3$ & $31 \pm 2$ \\
\hline Britannia & None & None & 3 & $38 \pm 1$ & $32 \pm 3$ & $31 \pm 2$ \\
\hline Britannia & $\mathrm{Ca}(0.07)$ & None & 1 & $7.0 \pm 0.5$ & $7 \pm 3$ & $14 \pm 1$ \\
\hline Britannia & $\mathrm{Ca}(0.03)$ & None & 1 & - & $10.0 \pm 0.5$ & $25 \pm 1$ \\
\hline Britannia & $\mathrm{Ca}(0.03)$ & DoeRun & 1 & - & $8.0 \pm 0.5$ & $14 \pm 1$ \\
\hline Britannia & $\mathrm{Sb}(2.5)$ & None & 1 & $65 \pm 2$ & $74 \pm 3$ & $131 \pm 3$ \\
\hline Britannia & $\mathrm{Sb}(2.5)$ & DoeRun & 1 & $71 \pm 3$ & $82 \pm 3$ & $112 \pm 3$ \\
\hline
\end{tabular}

Table 2. $\alpha$-activity for different types of $\mathrm{Pb}$ and $\mathrm{Pb}$ alloys at different times after lead production, measured using nuclear emulsions.

$2 \pi$ gas flow proportional counter of $4.9 \mathrm{~cm}^{2}$ sensitive area. The results of the measurements are summarized in Table 3. They confirm the lower activities of PbCa samples with respect to the $\mathrm{PbSb}$ ones, both for co-laminated and non co-laminated foils. 


\begin{tabular}{|c|c|c|c|c|c|c|c|c|c|}
\hline $\begin{array}{c}\text { Primary } \\
\text { lead }\end{array}$ & $\begin{array}{c}\text { Secondary } \\
\text { component } \\
(\%)\end{array}$ & $\begin{array}{c}\text { Colamination } \\
\text { lead }\end{array}$ & $\begin{array}{c}\text { Sample } \\
\text { thickness } \\
(\mathrm{mm})\end{array}$ & \multicolumn{5}{|c|}{$\begin{array}{c}\text { Time after production } \\
\text { (weeks) }\end{array}$} \\
\hline \multicolumn{3}{|c}{} & & 0 & 2 & 3 & 9 & 17 \\
\cline { 5 - 11 } & & \multicolumn{5}{c|}{$\begin{array}{c}\left.\text { Surface activity (counts } \mathrm{cm}^{-2} \mathrm{~d}^{-1}\right) \\
(10-20 \% \text { error })\end{array}$} \\
\hline Britannia & $\mathrm{Sb}(2.5)$ & None & 1 & 65 & 84 & 79 & 82 & \\
\hline Britannia & $\mathrm{Sb}(2.5)$ & DoeRun & 1 & 28 & 44 & 35 & 52 & \\
\hline Britannia & $\mathrm{Ca}(0.06)$ & None & 1 & - & - & - & 12 & 12 \\
\hline Britannia & $\mathrm{Ca}(0.06)$ & DoeRun & 1 & - & - & - & 14 & 10 \\
\hline DoeRun & $\mathrm{None}$ & DoeRun & 1 & 21 & - & - & - & - \\
\hline Britannia & $\mathrm{None}$ & None & 3 & 33 & - & - & - & - \\
\hline Britannia & $\mathrm{Ca}(0.07)$ & None & 3 & 6 & - & - & & - \\
\hline Britannia & $\mathrm{Sb}(2.5)$ & None & 3 & 42 & - & - & - & - \\
\hline
\end{tabular}

Table 3. $\alpha$-activity for different types of $\mathrm{Pb}$ and $\mathrm{Pb}$ alloys and times after lead production, measured using a $2 \pi$ gas flow proportional counter.

\subsection{Measurements with Surface Barrier Silicon Detectors}

Surface Barrier Si Detectors (SBSiDs), so called because the active volume (depleted region) is very close to the surface of the detector, allow $\alpha$-particle spectroscopy to the level of $30 \mathrm{keV}$ resolution with about $100 \%$ efficiency. Two different commercial Surface Barrier Silicon detectors (SBSiD-1 and SBSiD-2) were used in two different OPERA labs. The distance of the lead sample from the detector was $\sim 2 \mathrm{~mm}$ and $\sim 10 \mathrm{~mm}$ for SBSiD-1 and -2 , respectively. The measurements were done inside a vacuum chamber $\left(\sim 10^{-5}\right.$ mbar $)$. The energy was calibrated using mixed $\alpha$ sources of ${ }^{273} \mathrm{~Np},{ }^{241} \mathrm{Am}$ and ${ }^{244} \mathrm{Cm}$ for the SBSiD-1, and of ${ }^{239} \mathrm{Pu},{ }^{241} \mathrm{Am}$ and ${ }^{244} \mathrm{Cm}$ for the SBSiD-2. The calibration spectra are shown in Fig. 4.

Fig. 5 shows the energy spectra obtained for six different lead samples. Notice that for the PbSb $2.5 \%$ samples the events cluster around an energy of $5.3 \mathrm{MeV}$, confirming the nuclear emulsion data. The noise level is very low for energies above $1.5 \mathrm{MeV}$; below $1.5 \mathrm{MeV}$ there is some general noise which increases with decreasing energy. In Fig. 5 one observes only a minor structure at $\mathrm{E}$ $\sim 5.3 \mathrm{MeV}$ for $\mathrm{PbCa} 0.03 \%$; no structure is observed for $\mathrm{PbCa} 0.07 \%$. From these measurements one can confirm the preliminary conclusions reached at the end of Section 2.1, in particular that the $\alpha$-activity from ${ }^{210} \mathrm{~Pb}$ in $\mathrm{PbCa} 0.07 \%$ and $0.03 \%$ is much smaller than in $\mathrm{PbSb} 2.5 \%$.

Some PbSb $2.5 \%$ samples were chemically etched so that a thickness of 3 to $90 \mu \mathrm{m}$ of surface material was removed. The $\alpha$-radioactivity was measured before and at different times after etching. Some results are shown in Fig. 6. The surface radioactivity decreases immediately after etching but then it increases with time. For example, the $\alpha$-radioactivity was 18 tracks cm ${ }^{-2} \mathrm{~d}^{-1}$ right after the removal of $27 \mu \mathrm{m}$ of total surface thickness, 28 tracks $\mathrm{cm}^{-2} \mathrm{~d}^{-1} 7.3$ weeks after etching and 41 tracks $\mathrm{cm}^{-2} \mathrm{~d}^{-1} 14.5$ weeks after etching. This indicates an ongoing diffusion of the ${ }^{210}$ Po towards the lead surface. 

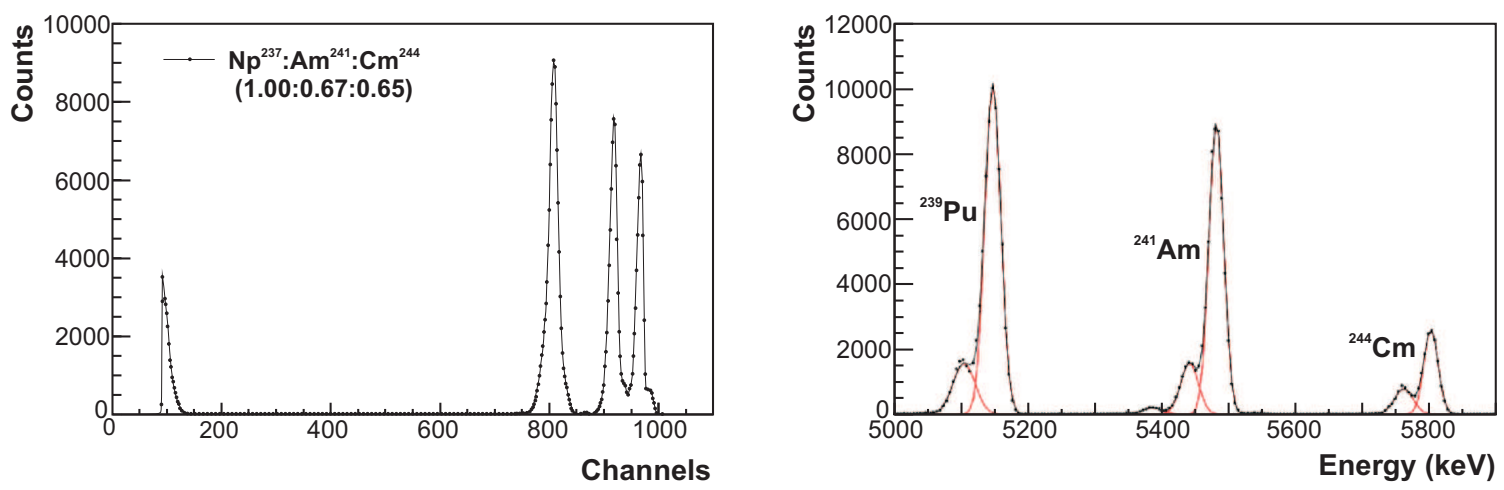

Figure 4. Left: calibration of SBSiD-1 with a mixed $\alpha$-source of ${ }^{273} \mathrm{~Np}(4.79 \mathrm{MeV}),{ }^{241} \mathrm{Am}(5.49 \mathrm{MeV})$ and ${ }^{244} \mathrm{Cm}(5.81 \mathrm{MeV})$. Right: calibration of SBSiD-2 with a mixed ${ }^{239} \mathrm{Pu}(5.16 \mathrm{MeV}),{ }^{241} \mathrm{Am}(5.49 \mathrm{MeV})$ and ${ }^{244} \mathrm{Cm}(5.81 \mathrm{MeV})$ alpha source.

Surface Barrier Silicon Detectors measurements were used also to evaluate the time variation of $\alpha$-radioactivity; the results are shown in Fig. 7 with those of CR39 detectors and discussed in Section 2.5.

\subsection{Measurements with CR39 nuclear track detectors}

In passive nuclear track detectors (NTDs) the damage produced by a charged particle can be enlarged through chemical etching and thus made visible under an optical microscope as a conical etch-pit (called a track). The etch-pit size is related to the particle Restricted Energy Loss (REL), i.e. the energy released inside a cylindrical region of about $10 \mathrm{~nm}$ diameter around the particle trajectory [15, 16]. The polymer CR39 is a widely used NTD. CR39 sheets $^{2}$ were first refreshed by etching them in a solution $8 \mathrm{~N} \mathrm{KOH}+3 \%$ alcohol at $75^{\circ} \mathrm{C}$ in order to remove previously recorded tracks from environmental radioactivity, mainly $\alpha$-tracks from radon [17]. About $120 \mu \mathrm{m}$ were removed from each side of the CR39 sheets; this thickness is large with respect to the $33.5 \mu \mathrm{m}$ range of $\alpha$-particles from radon in CR39.

The refreshed CR39 sheets were then placed in contact with the Pb samples. After exposure, the $\mathrm{CR} 39$ sheets were etched in a solution $6 \mathrm{~N} \mathrm{NaOH}$ at $70^{\circ} \mathrm{C}$ for 6 hours. The CR39 sheets were scanned and $\alpha$-tracks counted by a semi-automated optical microscope at a magnification of $250 \times$. A global efficiency of $\sim 65 \%$ for the detection of $5.3 \mathrm{MeV} \alpha$ 's was estimated; the detector energy threshold for $\alpha$-particles was about $3 \mathrm{MeV}$.

The results of the measurements are given in Fig. 7 and discussed in the following Section.

\subsection{Time evolution of $\alpha$-radioactivity}

The time dependence of the $\alpha$-activities of $\mathrm{PbSb} 2.5 \%, \mathrm{PbCa} 0.07 \%$ and $\mathrm{PbCa} 0.03 \%$ measured over $\sim 1$ year using SBSiDs and CR39 NTDs are plotted in Fig. 7 versus the time elapsed since the production of the lead alloy plates. The errors are statistical standard deviations. The solid lines are fits of the data to the expression $y=y_{0}+y_{1} e^{-t / \tau}$ ( $\tau \sim$ few months). For SBSiDs only the counts

\footnotetext{
${ }^{2}$ The CR39 was manufactured by the Intercast Europe, Spa, Parma, Italy. CR39 is a trademark of PPG industries. It is a polymer widely used for making lenses for sunglasses. The Intercast CR39 used here as NTD was made in a specific scientific production line.
} 

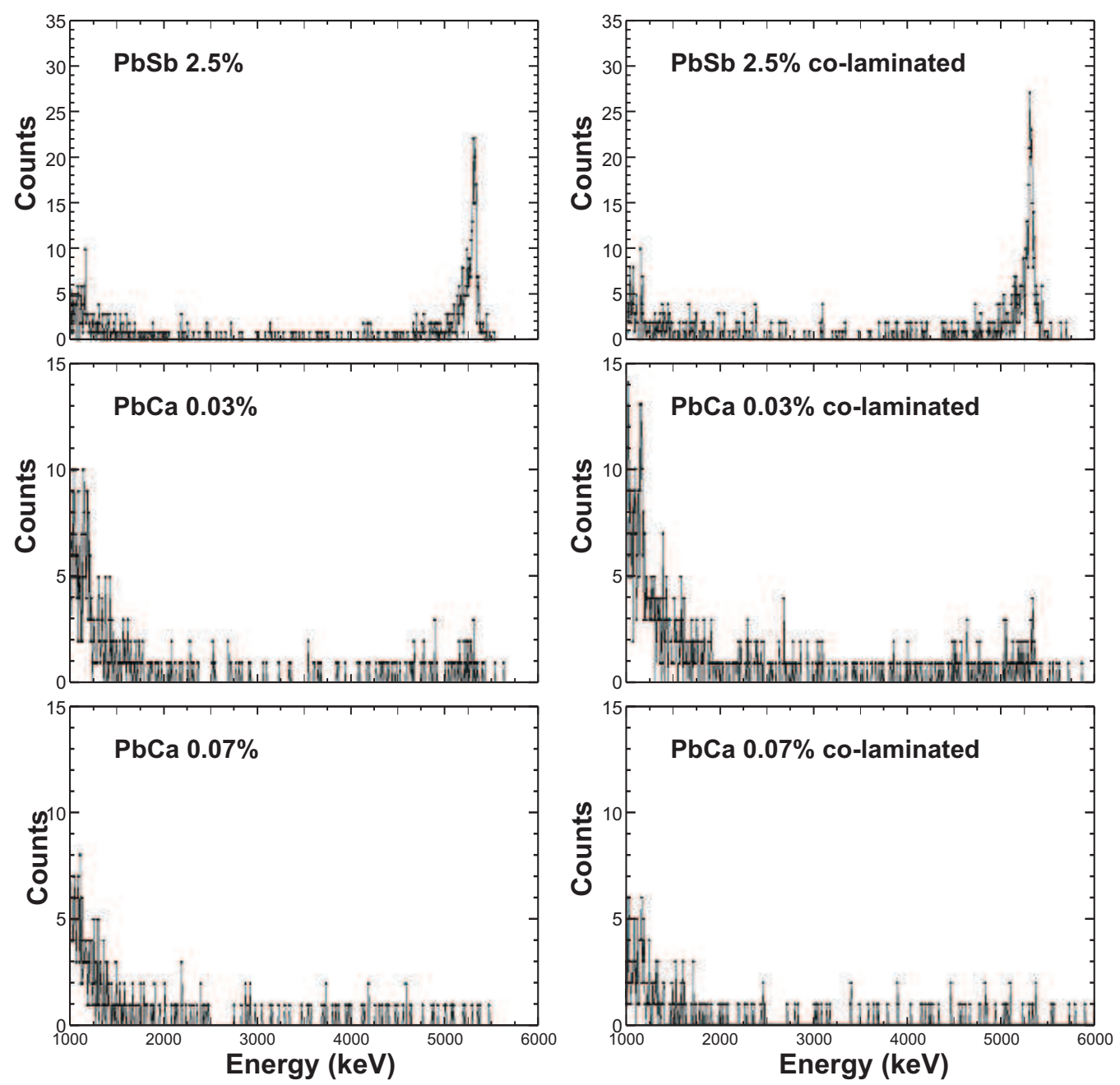

Figure 5. $\alpha$-radioactivity measurements with a SBSiD for six lead samples: on the left panels, from top $\mathrm{PbSb} 2.5 \%, \mathrm{PbCa} 0.03 \%$, and $\mathrm{PbCa} 0.07 \%$ samples; on the right panels, from top, co-laminated $\mathrm{PbSb} 2.5 \%$, $\mathrm{PbCa} 0.03 \%$, and $\mathrm{PbCa} 0.07 \%$ samples.

in the $4.0<E_{\alpha}<5.5 \mathrm{MeV}$ interval are considered. The activity in the first 70 days increases by about $40 \%$ for the $\mathrm{PbSb} 2.5 \%$ alloy; it increases by $10-20 \%$ for $\mathrm{PbCa} 0.07 \%$ and $0.03 \%$ alloys over a longer time interval. Over longer times the radioactivity of $\mathrm{PbCa} 0.07 \%$ and $0.03 \%$ increased a little further remaining at a very low level. The $\alpha$-radioactivity in $\mathrm{PbSb} 2.5 \%$ increased further and then remained constant at values $\sim 25$ times larger than for PbCa $0.07 \%$ and $0.03 \%$. Fig. $7 \mathrm{~b}$ shows that the $\alpha$-activity in PbSb $2.5 \%$ co-laminated with $30 \mu \mathrm{m}$ of pure DoeRun Pb behaves approximately as for $\mathrm{PbSb} 2.5 \%$ without co-lamination; therefore co-lamination does not reduce the surface $\alpha$-activity.

These results give quantitative information on the time dependence of the $\alpha$-radioactivity and confirm the preliminary conclusions reached using nuclear emulsions, presented in Section 2.1.

\subsection{Overview on the $\alpha$-radioactivity measurements}

The samples with the lowest $\alpha$-radioactivity are those with $\mathrm{PbCa} 0.07 \%$ and $0.03 \%$. For these 


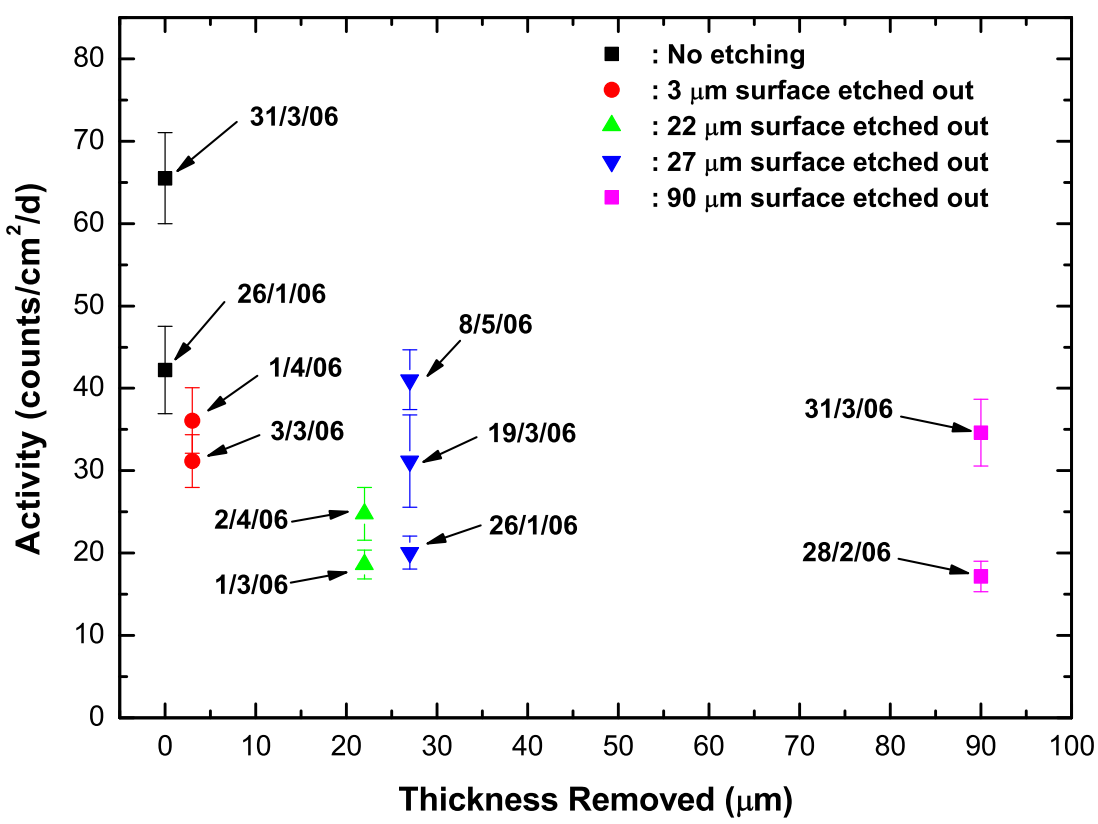

Figure 6. Surface $\alpha$-activity for PbSb 2.5\% lead samples versus the surface thickness removed by etching. The measurements were made at different times after etching, using a surface barrier silicon detector.

samples there is apparently no enhanced surface radioactivity. A possible explanation is that in the $\mathrm{PbSb} 2.5 \%$ samples the ${ }^{210} \mathrm{Po}$ atoms lie in a global potential which has a minimum at the edges of the sample. For the $\mathrm{PbCa} 0.07 \%$ and $0.03 \%$ samples it may be that the production process reduced the radioactivity by evaporation of ${ }^{210} \mathrm{Po}$ and/or that the global potential is more uniform.

\subsection{Monte Carlo simulations}

In order to better understand the features of the OPERA lead radioactivity, Monte Carlo (MC) simulations of the ${ }^{210} \mathrm{Po} \beta$-decay and of the ${ }^{210} \mathrm{Po} 5.3 \mathrm{MeV} \alpha$-decay inside the OPERA lead plates were made. Two set-ups were considered:

- a single lead plate with an area of $10 \times 10 \mathrm{~cm}^{2}$ in contact with an emulsion film with the same surface $(\alpha$-study);

- an OPERA brick, to evaluate the electron rate from $\beta$-decays.

The simulations were done using the GEANT 3.2 package. The emulsion radioactivity rate is defined by counting the arrival of an $\alpha$-particle inside the sensitive volume of the first emulsion layer. This implies a low threshold corresponding to an alpha range of $1 \mu \mathrm{m}$. We assumed for lead an activity of $80 \mathrm{~Bq} / \mathrm{kg}$ (Britannia lead).

If the $\alpha$ s are generated uniformly in the lead one obtains a flat $\alpha$ range distribution in emulsion as shown in Fig. 8a. Figs. 8b and 8c show the $\alpha$ emission points inside the lead and the energy spectrum of $\alpha$ s entering the emulsion, respectively. If the $\alpha$-emission is from a thin surface layer the $\alpha$-range distribution in emulsion is as shown in Fig. 9 for different thicknesses of the emitting layer. A comparison of the simulations shown in Fig. 9 with the measured spectra for $\mathrm{PbSb} 2.5 \%$ (Fig.3) indicates that $\alpha$ s are emitted from a surface thickness of $<1 \mu \mathrm{m}$ of the PbSb $2.5 \%$ alloy. 

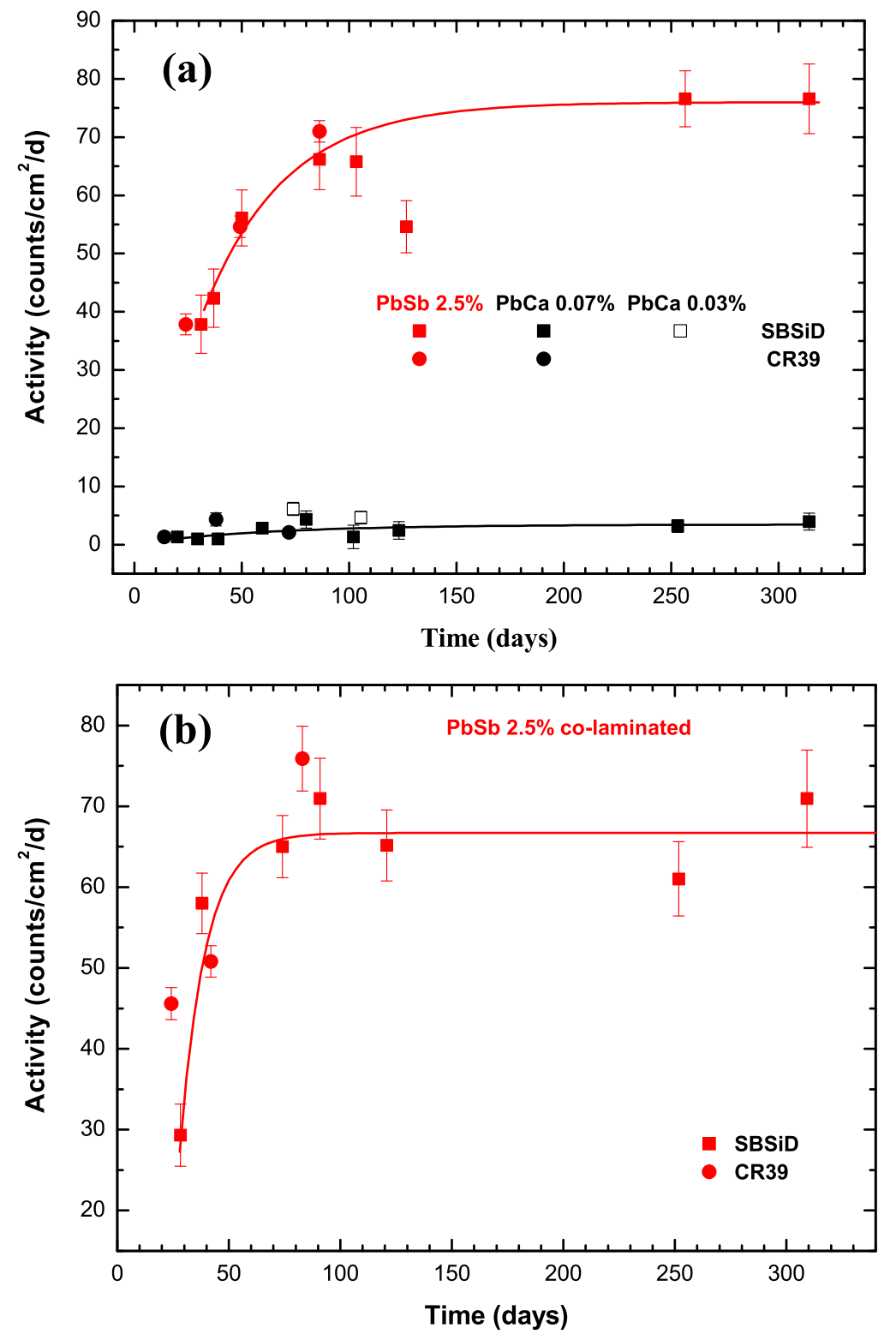

Figure 7. Time dependence of the alpha-activity from ${ }^{210} \mathrm{Po}$ (a) in $\mathrm{PbSb} 2.5 \%$, $\mathrm{PbCa} 0.07 \%$, $\mathrm{PbCa} 0.03 \%$ and (b) in PbSb $2.5 \%$ co-laminated with $30 \mu \mathrm{m}$ of pure DoeRun lead. The solid lines are fits to the data (see text).

A possible solution to protect the emulsion from the $\alpha$ s would be to interpose foils of at least $12 \mu \mathrm{m}$ of steel or $17 \mu \mathrm{m}$ of low radioactivity lead, which would stop the $5.3 \mathrm{MeV} \alpha \mathrm{s}$. This was the original purpose of the lead co-lamination.

The energy spectra obtained by SBSiDs were simulated by considering different thicknesses of the surface emission regions: $0.2 \mu \mathrm{m}, 0.5 \mu \mathrm{m}, 1 \mu \mathrm{m}$, and $2 \mu \mathrm{m}$. An experimental resolution of $50 \mathrm{keV}$ was folded in the distributions shown in Fig. 10. A further comparison of these simulations with the experimental data (Fig.5) allows us to state that the surface emitting region in $\mathrm{PbSb} 2.5 \%$ 

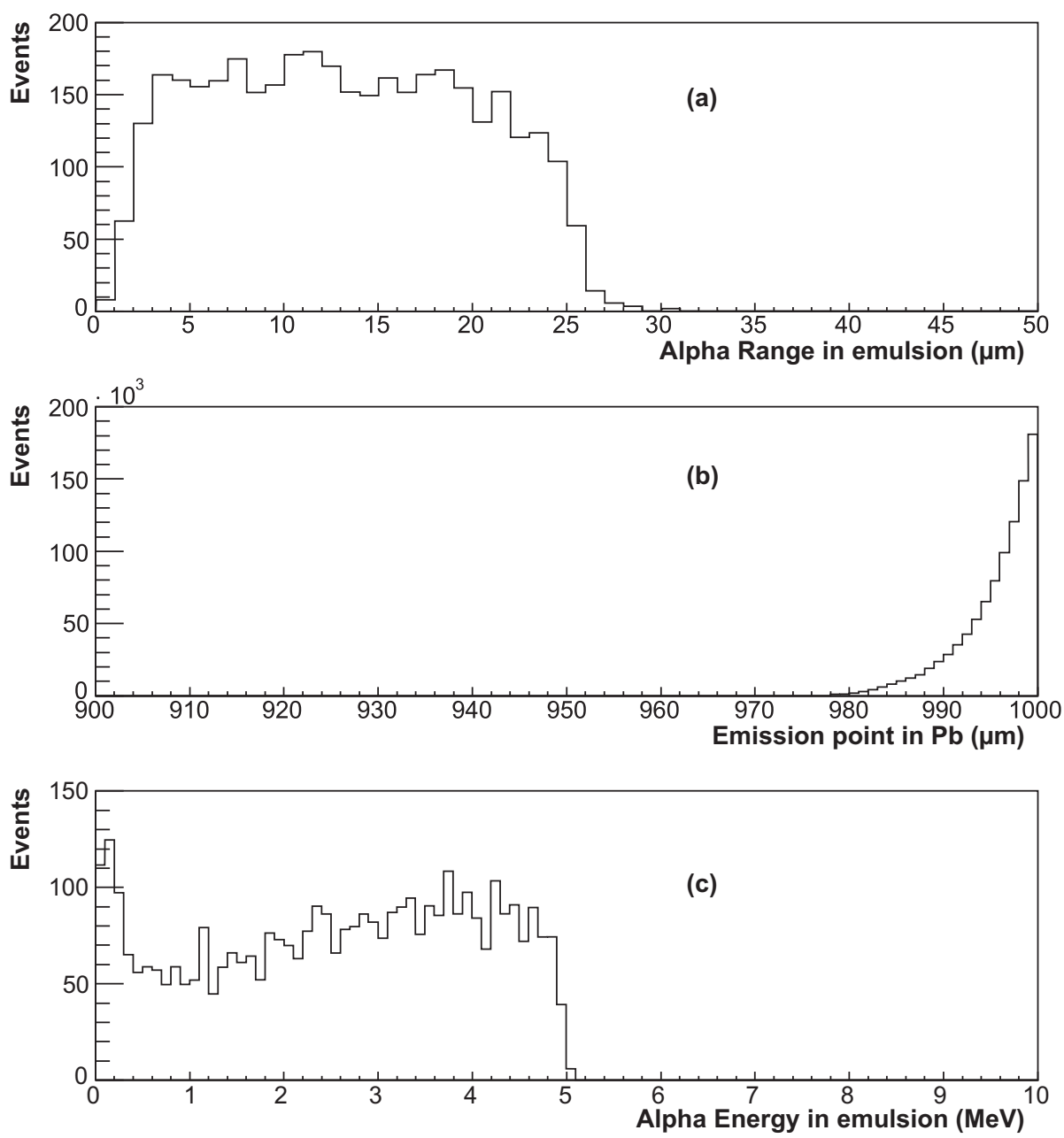

Figure 8. (a) Monte Carlo predicted range of alphas in nuclear emulsions for a uniform distribution of the $\alpha$-activity in the lead: the distribution is flat, very different from the measured spectra from $\mathrm{PbSb} 2.5 \%$, which indicate a surface effect. (b) Monte Carlo $\alpha$ emission point in lead: only alphas emitted from the last $20 \mu \mathrm{m}$ of lead are detected in emulsions. (c) Monte Carlo energy spectrum of the alphas entering the emulsion, reflecting the slowing down in the last $10 \mu \mathrm{m}$ of lead.

alloys has a thickness $<0.5 \mu \mathrm{m}$.

Monte-Carlo simulations of lead $\alpha$-radioactivity predicted rates of $\beta$-tracks in emulsion is $200 \beta$-tracks $\mathrm{cm}^{-2} \mathrm{~d}^{-1}$ for the single lead plate in contact with an emulsion film, and $622 \beta$-tracks $\mathrm{cm}^{-2} \mathrm{~d}^{-1}$ for emulsions inside a brick.

\section{Effects related to the brick packaging}

Tests were performed to investigate possible effects induced by the contact of the emulsions with different types of lead plates. For this purpose the fog in the emulsion, defined as the number of isolated dark grains per unit volume (grains per $1000 \mu \mathrm{m}^{3}$ ), was measured in the emulsion film in contact with the lead plates, in contact with other emulsion films and in emulsion films not in contact with lead. 

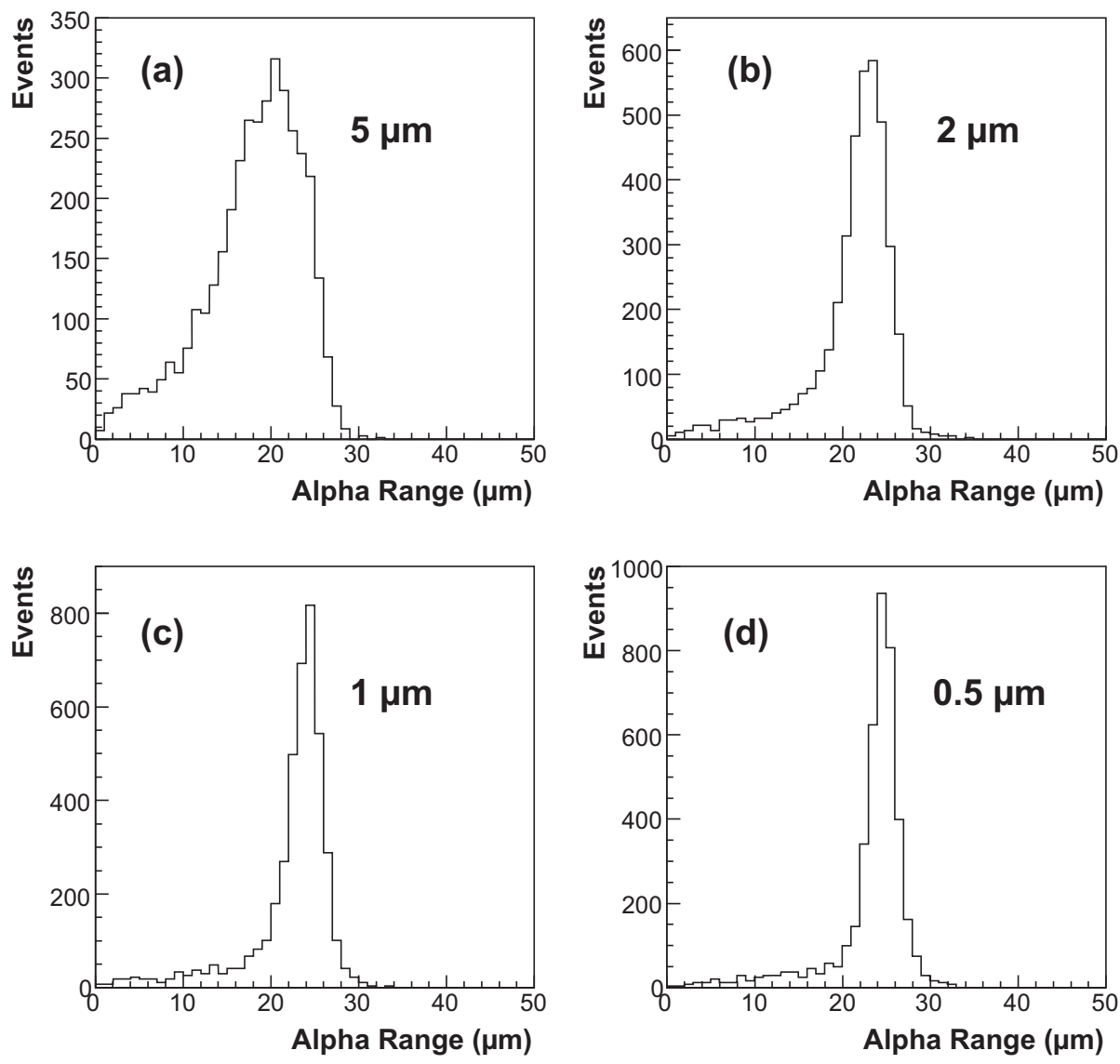

Figure 9. Monte Carlo studies: the range in emulsion of alphas emitted from different lead surface radioactive thicknesses: (a) $5 \mu \mathrm{m}$, (b) $2 \mu \mathrm{m}$, (c) $1 \mu \mathrm{m}$ and (d) $0.5 \mu \mathrm{m}$.

In past tests an increase of the fog was observed in nuclear emulsions packed in vacuum with $\mathrm{PbCa}$ lead alloy plates; on the other hand if the emulsion-lead contact was in air no fog increase was observed [12].

In order to further investigate the above effects, four OPERA-like bricks were assembled in different conditions using $\mathrm{PbCa} 0.07 \%$ lead plates: two bricks were packed à la OPERA using the standard OPERA brick cover (spider), one brick was sealed with a very small amount of air (10 cc), the other one was left open; the other two bricks were assembled without the OPERA brick spider, one open and one sealed with $10 \mathrm{cc}$ of air. The bricks were all stored in an oven at $35^{\circ} \mathrm{C}$. The fog was also measured in the emulsion film packed under vacuum without any lead and stored in the same oven with the four bricks.

After 5 weeks, the emulsion layer placed at the bottom side of the brick (bottom), the middle one (middle) and the one at the top (top) were developed and the fog density was measured. The results are shown in Fig. 11. The fog measurements performed automatically and checked manually gave values from 4 to 6.5 grains $/ 1000 \mu \mathrm{m}^{3}$, which are smaller than the fog in the emulsion packed under vacuum without lead.

A half-brick (23 emulsion films and 23 lead plates) was assembled using $\mathrm{PbSb} 2.5 \%$ and maintained for 8 months in the Gran Sasso underground laboratory inside a shield of very pure 

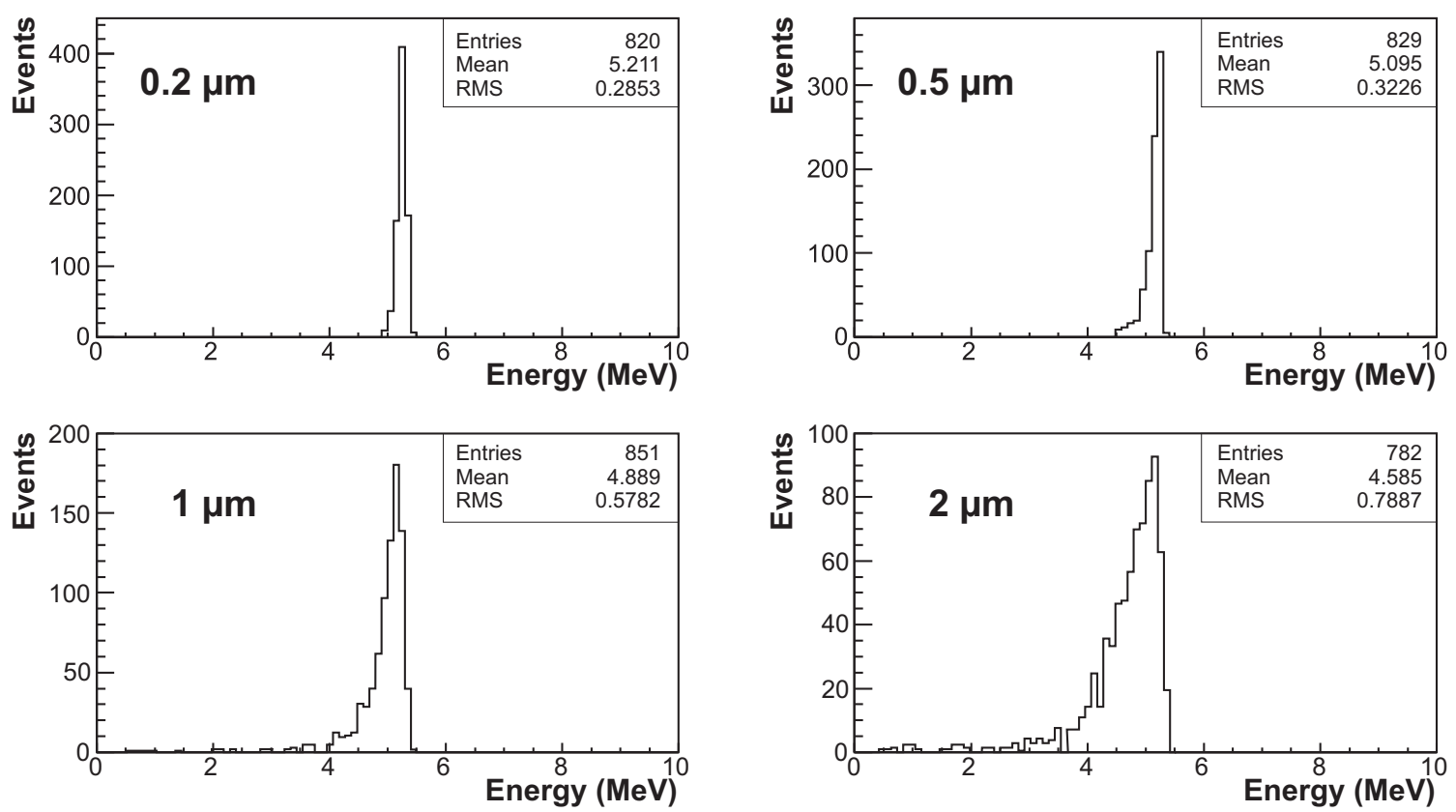

Figure 10. Monte Carlo predicted energy spectra in silicon surface barrier detectors, depending on the ${ }^{210} \mathrm{Po}$ effective thickness of the surface emission region.

copper and lead [12]. One emulsion in contact with the lead plate was developed and analysed: its outer surface was full of $\alpha$-tracks and had a very low fog density of $\sim 2.9$ grains $/ 1000 \mu \mathrm{m}^{3}$. This low fog level was probably connected with the ambient conditions of the underground lab.

\section{Effects of $\alpha$ - and $\beta$-radioactivity on emulsion scanning.}

To assess the effect of $\alpha$ and $\beta$-radioactivity on emulsion scanning, several tests were performed by exposing emulsions to different $\alpha$ - and $\beta$-radioactive sources. We also used $500 \mathrm{MeV}$ electrons from the INFN-LNF electron beam and $1 \mathrm{GeV}$ pions at the KEK accelerator. The $\alpha$ - and $\beta$ exposures were performed to mimic the $\mathrm{PbSb} 2.5 \%$ effect from 2 to 5 years of contact.

We evaluated the impact of different densities of $\alpha$ - and $\beta$-tracks on the performance of the automated miscroscopes described in Ref.[11] in terms of background and efficiency. The acquisition speed ( $20 \mathrm{~cm}^{2} /$ hours) did not decrease even with an $\alpha$ dose of $400 \alpha /$ view but the number of fake microtracks increased by more than a factor of 2.5 with respect to the unexposed zones. Almost all the reconstructed base tracks in the $\alpha$-and $\beta$-exposed zones were bad tracks and most of them could be rejected with a simple quality cut; the radiation exposure increased the base track density up to a factor of 2 . The effects will be considerably smaller in the case of $\mathrm{PbCa} 0.07 \%$ or $0.03 \%$

Overall, we have not encountered problems on the emulsion scanning at the level of track finding. Further investigation will be carried out in order to evaluate the effects on the interaction vertex reconstruction and event analysis. 


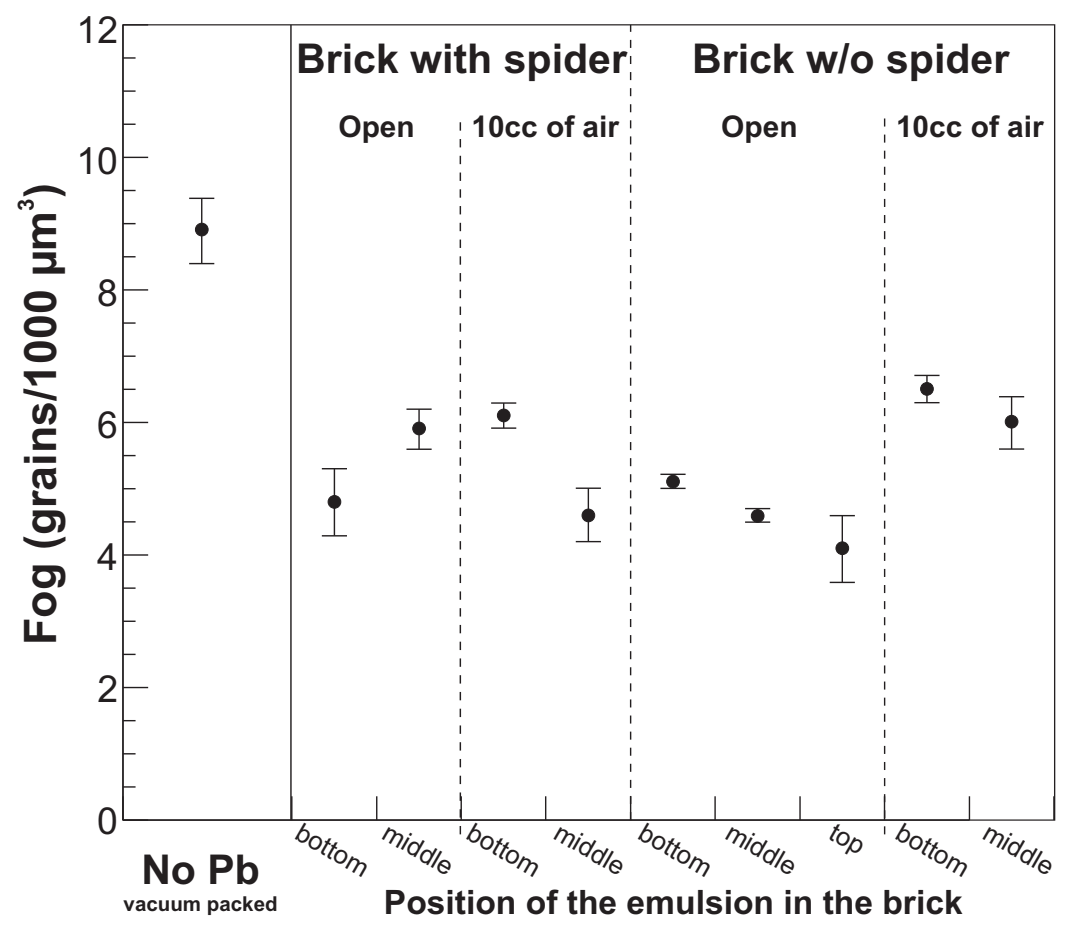

Figure 11. Fog measurements in emulsions placed in an OPERA-like brick in contact with $\mathrm{PbCa} 0.07 \%$ plates and stored for 5 weeks in an oven at $35^{\circ} \mathrm{C}$. From the left: emulsion packed under vacuum, without any lead, brick packed using the OPERA brick spider (open or with $10 \mathrm{cc}$ of air), brick packed without the spider (open or with $10 \mathrm{cc}$ of air). Error bars are total errors obtained by adding in quadrature systematic and statistical uncertainties (measurements performed automatically with an ESS).

\section{Conclusions}

In the OPERA neutrino oscillation experiment, nuclear emulsion films are in contact with lead plates and packed together in a basic detector unit called brick. The lead with the lowest radioactivity practically available on the market was chosen. In order to ensure adequate mechanical properties, other chemical elements (like $\mathrm{Ca}$ or $\mathrm{Sb}$ ) are added to the lead.

The effective radioactivity acting on the emulsion films was found to depend on the type and on the concentration of the added chemical element. In particular, evidence was found for the occurrence of a migration of ${ }^{210} \mathrm{Po}$ towards the surface of $\mathrm{PbSb} 2.5 \%$ samples, in contact with the emulsions. Monte Carlo calculations give results consistent with this interpretation of the high radioactivity which, in certain conditions, affects the emulsions. The comparison of experimental data with Monte Carlo simulations indicated that the thickness of the $\alpha$-emitting region in $\mathrm{PbSb}$ $2.5 \%$ samples is smaller than $0.5 \mu \mathrm{m}$.

The main measurements are summarized as follows. The $\alpha$-radioactivity is lower for the $\mathrm{PbCa}$ $0.07 \%$ and $0.03 \%$ alloys. For PbSb $2.5 \%$ it is 25 times larger than in $\mathrm{PbCa} 0.07 \%$. An increase with time of the surface activity of PbSb $2.5 \%$ samples was observed in the first 4 months after production; it then remained constant at a level of $\sim 65$ tracks cm ${ }^{-2} \mathrm{~d}^{-1}$ (at the ${ }^{210} \mathrm{Po}$ peak). No significant increase was observed for the $\mathrm{PbCa} 0.07 \%$ and $\mathrm{PbCa} 0.03 \%$ over a period of more than 
1 year for all energy intervals; the radioactivity remained at the level of 1-3 tracks $\mathrm{cm}^{-2} \mathrm{~d}^{-1}$ at the energy peak corresponding to ${ }^{210}$ Po decay. Co-lamination with thin layers of pure lead to protect the emulsions from $\alpha$-radioactivity was found to be technically difficult and hence not to be a viable solution.

An increase of the fog in emulsions packed in vacuum was observed. This effect is negligible for the bricks packed in air rather than in vacuum, as currently done for OPERA emulsions. The packing technique for the bricks was decided accordingly to this observation.

The presence of $\alpha$ - and $\beta$-rays from the lead radioactivity may affect the track reconstruction in the emulsions. However, it was found that the spurious tracks (or more precisely base tracks) can be removed by a simple quality cut. The reconstruction efficiency for some types of event has to be studied and further tests are in progress. The visual inspection of candidate events is envisaged to further improve the situation and eliminate problems.

On the basis of the results obtained it was decided to use for OPERA the $\mathrm{PbCa} 0.03 \%$ alloy, which has good mechanical properties and is safe with respect to $\alpha$-radioactivity and chemical effects.

\section{Acknowledgements}

We acknolewdge the cooperation with the group of Prof. V. Palmieri of INFN-LNL for discussions, advices and preparation of some etched samples. We thank the Health Physics Group of the Physics Department of Bologna, in particular Dr. M. P. Morigi, and Dr. M. Bettuzzi for providing the SBSiD detector equipment and for helpful suggestions. We are grateful to Dr. Z. Sahnoun for her collaboration.

We warmly acknowledge funding from our national agencies: Fonds de la Recherche Scientifique - FNRS et Institut Interuniversitaire des Sciences Nucléaires for Belgium, MoSES for Croatia, IN2P3-CNRS for France, BMBF for Germany, INFN for Italy, the Japan Society for the Promotion of Science (JSPS), the Ministry of Education, Culture, Sports, Science and Technology (MEXT) and the Promotion and Mutual Aid Corporation for Private Schools of Japan for Japan, SNF and ETHZ for Switzerland, the Russian Foundation for Basic Research grants 06-02-16864-a and 08-02-91005-CERN-a for Russia, the Korea Research Foundation (KRF-2007-313-C00161) for Korea.

We thank INFN for providing fellowships and grants to non Italian researchers. We thank ILIAS-TARI for access to the LNGS research infrastructure and for the financial support through EU contracts P2006-01-LNGS and P2006-16-LNGS.

We are finally indebted to our technical collaborators for the excellent quality of their work over many years of design, prototyping and construction of the detector and of its facilities.

\section{References}

[1] M. Guler et al., OPERA Proposal CERN/SPSC 2000-028, CERN/SPSC 2001-025;

R. Acquafredda et al., New. J. Phys. 8 (2006) 303;

A. Anokina et al., arXiv:0804.1985 [physics.ins-det].

[2] The CNGS project: http://proj.cngs.web-cern.ch/proj-cngs/. 
[3] K. S. Hirata et al., Phys. Lett. B205 (1988) 416.

[4] S. P. Ahlen et al., Phys. Lett. B449 (1995) 481.

[5] M. Ambrosio et al., Phys. Lett. B434 (1998) 451; Phys. Lett. B517 (2001) 59; Eur. Phys. J. C36 (2004) 323.

[6] W.W. Allison et al., Phys. Lett. B449 (1999) 137; Phys. Rev. D72 (2005) 052005.

[7] Y. Fukuda et al., Phys. Rev. Lett. 81 (1998) 1562. Y. Ashie et al., Phys. Rev. Lett. 93 (2004) 101801. J. Hosaka et al., Phys. Rev. 97 (2006) 0320002. K. Kanayuti, Recent SK results, EPS 2007 Conf., Manchester.

[8] M. H. Ahn et al., Phys. Rev. D74 (2006) 072003.

D. G. Michael et al., Phys. Rev. Lett. 97 (2006) 191801. MINOS Collaboration, Preliminary Results from MINOS on $v_{\mu}$ Disappearance Based on an Exposure of $2.5 \times 10^{20} 120 \mathrm{GeV}$ Protons on the NuMI Target, arXiv:0708.1495v2 [hep-ex].

[9] M. F. Kaplon, B. Peters, and D. M. Ritson, Phys. Rev. 85 (1952) 900.

[10] T. Nakamura et al., Nucl. Instrum. Meth. A556 (2006) 80.

[11] N. Armenise et al., Nucl. Instrum. Meth. A551 (2005) 261. M. De Serio et al., Nucl. Instrum. Meth. A554 (2005) 247.

L. Arrabito et al., Nucl. Instrum. Meth. A568 (2007) 578; J. Inst. 2 (2007) p02001; J. Inst. 2 (2007) p05004; hep-ex/0506078.

[12] E. Barbuto et al., Nucl. Instrum. Meth. A525 (2004) 485.

C. Sirignano, PhD thesis, University of Salerno (2006).

[13] J. F. Ziegler, M. D. Ziegler, J. P. Biersack, SRIM 2003, The Stopping and Range of Ions in Matter; www.srim.org; Copyright: SRIM.com, 2003.

[14] A. Zastawny et al., Int. J. Radiat. Appl. Iso. A43 (1992) 1147; Appl. Radiat. Iso. 39 (1988) 447; Appl. Radiat. Iso. 40 (1989) 19.

[15] S. Cecchini et al., Nuovo Cimento A109 (1996) 1119; Radiat. Meas. 34 (2001) 55; Astropart. Phys. 1 (1993) 369.

[16] S. Balestra et al., Nucl. Instrum. Meth. B254 (2007) 254.

[17] C. Arpesella et al., Health Physics 72 (1997) 629. 